Paideusis

\title{
Welcoming Confusion, Embracing Uncertainty: Educating Teacher Candidates in an Age of Certitude
}

\section{Mordechai Gordon}

Volume 15, Number 2, 2006

URI: https://id.erudit.org/iderudit/1072677ar

DOI: https://doi.org/10.7202/1072677ar

See table of contents

Publisher(s)

Canadian Philosophy of Education Society

ISSN

0838-4517 (print)

1916-0348 (digital)

Explore this journal

Cite this article

Gordon, M. (2006). Welcoming Confusion, Embracing Uncertainty: Educating Teacher Candidates in an Age of Certitude. Paideusis, 15(2), 15-25.

https://doi.org/10.7202/1072677ar
Article abstract

This essay challenges the current emphasis on certainty, measurement and control in the field of education and the widespread view that confusion hurts students. Drawing on some recent analyses of Socrates as well as my own interpretation of his dialogues, I discuss how he might respond to the quest for certainty in education. Socrates would want us to welcome confusion and embrace uncertainty, and urge us to reconceptualize the quest for certainty as an ongoing process aimed at increasing complexity and enhancing understanding. Based on the insights I gleaned from Socrates, I argue that creating a space for perplexity and uncertainty in our classrooms is crucial for the goal of fostering citizens who are critical and independent thinkers. I conclude this essay by proposing a number of ways in which teacher educators can help their students welcome confusion and embrace uncertainty.
This document is protected by copyright law. Use of the services of Erudit (including reproduction) is subject to its terms and conditions, which can be viewed online.

https://apropos.erudit.org/en/users/policy-on-use/ 


\title{
Welcoming Confusion, Embracing Uncertainty: Educating Teacher Candidates in an Age of Certitude
}

\author{
MORDECHAI GORDON \\ Quinnipiac University, USA
}

This essay challenges the current emphasis on certainty, measurement and control in the field of education and the widespread view that confusion hurts students. Drawing on some recent analyses of Socrates as well as my own interpretation of his dialogues, I discuss how be might respond to the quest for certainty in education. Socrates would want us to welcome confusion and embrace uncertainty, and urge us to reconceptualize the quest for certainty as an ongoing process aimed at increasing complexity and enhancing understanding. Based on the insights I gleaned from Socrates, I argue that creating a space for perplexity and uncertainty in our classrooms is crucial for the goal of fostering citizens who are critical and independent thinkers. I conclude this essay by proposing a number of ways in which teacher educators can help their students welcome confusion and embrace uncertainty.

\section{Introduction}

Plato's dialogue Meno is a discussion of the nature of virtue and in particular of the question of whether virtue can be taught. Menon, a wealthy young nobleman, approaches Socrates and asks him the following questions: "Can you tell me, Socrates_can virtue can be taught? Or if not, does it come by practice? Or does it come neither by practice nor by teaching, but do people get it by nature, or in some other way?" (Warmington \& Rouse, 1956, p. 28) When Socrates hears these questions he immediately stops Menon and says to him something like this: "Wait a minute, my dear Menon, how can I talk about whether virtue can or cannot be taught, when I don't even know what virtue is!" In other words, Socrates asks: how can I talk about the qualities or attributes of something without first defining it, that is, before having a fairly clear understanding of what this concept means?

Regardless of whether Socrates is actually telling the truth when he claims that he does not know what virtue is, he succeeds in convincing Menon that he does not know and gets the confident young nobleman to attempt to define virtue. And so in the opening pages of the dialogue, Menon makes several attempts to define virtue, all of which are ultimately refuted by Socrates. In some cases, Socrates rejects Menon's explanations because they are actually particular examples or parts of virtue and not a general definition of this concept as a whole. In other cases, Socrates shows that what Menon has offered is illogical or does not make sense. Finally, after failing at numerous attempts to define virtue, Menon becomes very frustrated with Socrates and admits that he is confused and even stunned:

(C) Copyright 2006. The author, Mordechai Gordon, assigns to Paideusis the right of first publication and educational and nonprofit institutions a non-exclusive license to use this document for personal use and in courses of instruction provided that the article is used in full and this copyright statement is reproduced. Any other usage is probibited without the express permission of the author. 
And now you seem to me to be a regular wizard, you dose me with drugs and bewitch me with charms and spells, and drown me in puzzledom... Really and truly, my soul is numb and my mouth is numb, and what to answer you I do not know. Yet I have a thousand times made long speeches about virtue, before many a large audience, and good speeches, too, as I was convinced; but now I have not a word to say at all as to what it is. (Warmington \& Rouse, 1956, p. 40)

Clearly, Menon is in an uncomfortable state of mind now, a state of bewilderment and frustration that people usually find very disturbing. Yet one way to interpret the process that Menon goes through, is to consider the possibility that, educationally speaking, he may be better off in his present state of confusion and numbness than when he thought he knew what virtue meant. At the beginning of the dialogue, Menon came across as very confident and sure of himself, ${ }^{1}$ and he was not really open to examine his beliefs about virtue, merely repeating his already formed ideas. After Socrates demonstrates that all of his ideas about virtue are problematic, Menon begins to doubt himself and to question many of the beliefs he previously took for granted. Being confused and facing his own limitations, Menon is probably much more open and willing than he was before to search together with Socrates for a good definition of virtue, as illustrated by the fact that he continues to investigate this concept further and deeper than ever before. As Daniel Pekarsky notes:

Socrates's conversation partner, or student, thus resembles the hero in a Greek tragedy who begins the drama in a state of hubris, or conceit and is, partly for this very reason, led into a fall. The degradation or shame that accompanies this fall carries, in the tragedy, an important compensation; the hero gains new insight into himself or herself and the human condition. The student of Socrates travels a similar journey: from complacent self-confidence to perplexity and humility-and although new insight does not necessarily accompany this transformation (except perhaps an important insight into the bankruptcy of one's own previous condition), this transformation makes possible a journey in the direction of truth which could not previously have been undertaken. (Pekarsky, 1994, p.122)

What is the implication for the education of new teachers that can be gleaned from this particular interpretation of what happens to Menon and from Socrates' educational agenda in general? One noteworthy lesson is that whereas the state of confusion may be psychologically uncomfortable or unsettling, educationally speaking it is not necessarily a bad thing. Indeed, confusion and uncertainty ${ }^{2}$ often lead people to search more, to question previously cherished beliefs, and to take on a new perspective. In contrast, when people are sure that they understand and know something, they are much less likely to examine it critically. Yet such examinations are essential, as the dialogues of Plato illustrate, because they always lead us to a deeper and more complex understanding of the concept or issue that is being investigated. In short, what I am suggesting is that teacher educators and teachers in general who embrace confusion, questioning, and a sense of wonder in their classrooms are helping rather than hurting their students. In this essay, I would like to use this insight to challenge the current emphasis on certainty, measurement and control in the field of education as well as the belief that uncertainty hurts students.

\footnotetext{
${ }^{1}$ When Menon initially attempts to define virtue he says: "That is nothing difficult, my dear Socrates. First, if you like, a man's virtue, that is easy..." (Warmington \& Rouse, 1956, p. 29; emphasis added).

2 Although I recognize that 'confusion' and 'uncertainty' are often used interchangeably, I distinguish them. By 'confusion' I mean 'lack of clarity'; and by 'uncertainty' I mean 'lack of certainty'. According to this usage, a person can be totally clear about something that is very uncertain. Confusion is a psychological state, but uncertainty is an ontological condition that often pertains to how things are in the world.
} 


\section{The Quest for Certainty in Education}

During my tenure as a teacher educator, I have repeatedly noticed that many students come to us looking for recipes, for a bag of tricks that they can take with them and apply in their classrooms. They assume that if they could just acquire these techniques and skills they will be good teachers or at least survive in the urban public schools. While I am not against teaching students some worthy techniques in classroom management, for instance, I seriously doubt that knowing these techniques will make them good teachers or even allow them to survive in many of our nation's public schools. Of course, given the predominance of the technocratic view of education and schooling in our society, such an attitude is understandable. Ann Watts Pailliottet and Thomas Callister point out that:

By making the educational process technical, we pattern the curriculum after a stair-step model of linear fact-by-fact learning, trivialize teaching as a series of generic "how to's" or formulaic "hints and tips," and too often reduce the act of learning to simple models of behavioral stimulus-response mechanisms. (Paillotet \& Callister, 1999, p. 166)

Thus who can blame teacher candidates for wanting recipes when most of the conversations they hear about schooling are full of the language of accountability, measurement and testing. As Louise Berman writes, "what is seen, spoken, and tested becomes the essence of education" (Berman, 1999, p. 19). In many educational institutions, both teachers and students are conditioned to join the quest for certainty and focus on those learning objectives that can actually be measured. Following Dewey, the "quest for certainty" refers here to our desire to gain a sense of security and power over situations in which we feel impotent because we do not have the knowledge or the technical means to control them (Dewey, 1988, pp. 21 \& 176). This quest implies an unwillingness to live with the inherent complexities and risks of education. Paul Smeyers describes this unwillingness vividly:

We crave for the general in the particular in order to cope with the dazzling differences we are confronted with, cherishing the illusion that this approach will keep us from getting lost amid the contingency of the world. We like to fantasize that issues of power can be ignored, that knowledge can be made safe from factors that distort it. Worst of all, we behave as though even if we cannot fully meet the requirements implied by these demands, we should nevertheless try to get as far down this road as we can. (Smeyers, 2005, p. 180).

The efforts to eliminate complexity and control risks undoubtedly pose serious problems for the curriculum as well as teaching and learning. For instance, the quest for certainty in education has contributed to the narrowing of the curriculum, the proliferation of instructional practices aimed at teaching to the test, and the marginalization of important dimensions of our beings like developing the imagination and a sense of mystery. The irony is, as many contemporary educators have recognized, that teaching in particular and the life of schools in general are marked by uncertainty, complexity, and instability. According to Joseph McDonald, "teaching a class of students is highly complex work. It entails numerous ambiguities, including the fundamental one concerning the relationship between one's teaching efforts and the effects on students' learning" (McDonald, 1986, p. 360). Teaching is an uncertain and complex activity because "no teacher can be sure how a lesson will go or exactly what a student will learn. No one can know which teaching approach will guarantee success for particular groups of students" (Floden \& Buchmann, 1993, p. 373). Other educators who have closely studied the various aspects of teachers' work have come to the same conclusion about the uncertain, ambiguous, and complex nature of this profession (Jackson, 1990; Schön, 1983).

Much like education, human reality and our everyday experience are marked by surprises and confusions and they cannot be characterized in black and white or clear-cut terms. Indeed, this reality is full of controversies, ambiguities, shades of gray, and uncertainties. There is never just one way to 
analyze an event in history, a Shakespearean play, a problem in science, or an argument between two friends for that matter. In fact, what makes human existence so fascinating and meaningful is precisely the ambiguities, uncertainties and struggles that characterize our lives. Things that are complex are inherently uncertain and vice versa. As such, they are difficult to handle, and in trying to understand them, we can easily end up getting confused. We do not like to be confused because it is uncomfortable in many ways, and so in the interest of not being confused, we usually demand things be certainunambiguous, organized, and simple. Yet if uncertainty and complexity characterize our world, then we need to overcome our fear of confusion. We need to welcome confusion as an indication that we are seeing and dealing with the complexity inherent in the world. Unless we begin to welcome confusion and work with it, we will continue to fear it and struggle to live with uncertainty and complexity.

So what accounts for our reluctance to welcome confusion and embrace uncertainty? What accounts for the overemphasis on standardization, testing and measurement in schools as well as my students' desire to acquire those tricks and techniques that will supposedly guarantee their success? One reason, emphasized by Dewey, is that the quest for certainty is an expression of our desire for psychological security in the face of the uncertainty of practical life:

It would be possible to argue...that failure to make action central in the search for such security as is humanly possible is a survival of the impotency of men in those stages of civilization when he had few means of regulating and utilizing the conditions upon which the occurrence of consequences depend. As long as man was unable by means of the arts of practice to direct the course of events, it was natural for him to seek an emotional substitute; in the absence of actual certainty in the midst of a precarious and hazardous world, men cultivated all sorts of things that would give them the feeling of certainty. (Dewey, 1988, p. 26)

To be sure, Dewey was talking about the Ancient Greeks' yearning for emotional security in a world in which there was a great deal of uncertainty and physical danger and people did not have the knowledge and tools to control this peril. Yet, I would argue that his point is equally valid for the realm of education, a realm that is inherently complex and unpredictable. That is, the quest for certainty in education is a result of our desire to gain a sense of psychological security and more control of a field that is fundamentally indeterminate. For instance, the current emphasis on standardization and testing in the Unites States can be viewed as an attempt to better control students' learning and behavior in a time of declining school performance and high student drop-out rates. In the case of my students, the search for recipes can be interpreted as a desire to attain some emotional comfort and stability in the face of the chaos they experience in the classrooms they observe and work in.

Another reason for the overemphasis on the quest for certainty and exact measurement is the resurgence in the United States of a very limiting notion of research and knowledge. For instance, the 2001 No Child Left Behind Act has mandated an emphasis on "scientifically based research." In this context, scientifically based research means "research that involves the application of rigorous, systematic, and objective procedures to obtain reliable and valid knowledge relevant to education activities and programs" (Horn, 2004, p. 196). This type of research relies on measurements or observational methods that provide reliable and valid data across a wide variety of studies. Knowledge is, therefore, those insights and data which can be accurately measured or verified by empirical scientific methods. Critics of this definition charge that it "will result in strictly controlled scientific studies that will be narrowly experimental and quasi-experimental. They fear the lack of latitude that would allow a diversity of research ranging from qualitative studies to literary explorations of educational issues" (Horn, p. 198). One implication of the dominance of a narrow definition of scientifically based research is that it is likely to be used to exclude other important sources of knowledge such as intuition, imagination, feeling, and spiritual encounters.

In my own foundation of education classes, while I try to resist the temptation to give in to my students' desire for recipes and definitive answers for their questions, I am not unaffected by the quest 
for certainty that characterizes education and my own situation as an untenured professor. Concerned with addressing my students' needs and wanting them to like me, I usually yield to their requests for more prescriptive instructions and guidelines than I am comfortable with to the various assignments in the course. More importantly, I am rarely able to maintain a sense of mystery and uncertainty concerning my students' unresolved questions for the duration of the entire semester. Instead of preserving the tension for at least a few lessons, I often attempt to immediately clarify students' confusions and alleviate the doubts that emerge regarding the basic concepts we are learning. As such, I struggle with the challenge to embrace uncertainty, often preferring simplicity over complexity and clarity over confusion. This essay explores how Socrates might respond to the quest for certainty in education described above. After analyzing the significance of Socrates' position on confusion and certainty, I discuss a number of valuable implications that this view has for teacher education.

\section{Socrates and the Quest for Certainty}

Anyone familiar with the legacy of Socrates as it appears in the dialogues of Plato, knows that he loved to wrestle with big questions and problems and devoted his time to dialogue and the life of the mind. Socrates was relentless in his search for truth, and was an expert at examining the opinions of his dialogue partners, evaluating them from multiple perspectives to see if they held up to the test of reason and experience. Perhaps this is one of the reasons why many of the Socratic dialogues seem to go around in circles, analyzing the same problem from different points of view, but never really reaching a definitive answer. Yet, while it is true that Socrates does not provide us with conclusive definitions of virtue, justice, or love, he does help us gain a better understanding of these very complex and rich concepts. As such, Socrates embodies what it means to be a critical thinker: a person who takes nothing for granted and continuously engages in the process of questioning, analyzing, and revising his ideas.

To be perfectly clear, the Socrates that I am talking about is the one depicted in the earlier dialogues of Plato, the one that Richard Smith refers to as the dialectical Socrates as opposed the metaphysical one (Smith, 2005, p. 146). The latter is the one that believes in the existence of universal truths, whereas the former is clearly aware of the nonfoundational character of truth. According to Pádraig Hogan, in the earlier dialogues, like the Gorgias, Protagoras, and Euthyphro, Socrates emphasizes that "limitation and fallibility are inescapable features of human efforts to understand the highest truth to which we can aspire: truths about humans themselves, their experienced world, and the significance of their own place in it" (Hogan, 2005, p. 197). Thus, the dialectical Socrates was aware of the limitations of human understanding and the perspectival nature of truth. Yet, he cherished the educational encounters, the exchange of viewpoints, and the search for truth that the dialogues provided him. As Hogan argues, Socrates' search for truth 'involves an interplay with perspectives and horizons of understanding that are sometimes disconcerting, calling into question what one has already understood and made one's own" (Hogan, p. 197).

How would Socrates respond to the quest for certainty in education, which I have described as the efforts to eliminate complexity and control risks? Socrates would probably urge us to counter this trend with the kind of reflexive criticism he employs in the early dialogues. He would insist that the efforts to minimize complexity and risks in education are likely to lead us to less rather than more understanding of the problems that plague this field. For Socrates, the quest for truth and certainty should be reconceptualized as an ongoing process aimed at increasing complexity and enhancing understanding. It is a journey one takes with others in which the problems are continuously evaluated from fresh perspectives. Hogan summarizes this point well:

Defensible educational efforts have everything to do with a joint renewal of attentive listening and with the readiness to take risks for defensible learning. In fact, from an educational point 
of view..., each of the early Socratic dialogues can be seen as just such an attempt to learn anew in the company of others. Understanding - of oneself, of others, of an issue at stake might thus be bettered if one remains open to criticism and revision and without laying claim to any final mastery. (Hogan, 2005, p. 199).

Even though the dialectical Socrates recognizes the futility of trying to arrive at universal truths, he nonetheless insists that we should actively and continuously search for knowledge and truth. For instance, at the end of the Meno, Socrates finally proposes a tentative answer to the question about the character of virtue, suggesting that it comes to us neither by teaching nor from nature but by "divine dispensation." However, Socrates seems unsure about his own explanation and maintains that "we shall only know the truth about this clearly when, before enquiring in what way virtue comes to mankind, we first try to search out what virtue is in itself" (Warmington \& Rouse, 1956, p. 68). Thus he comes back to the same argument he made at the opening of the dialogue when Menon first asked him whether virtue could be taught. In returning to the point of departure, which occurs in other dialogues as well, Socrates is implying that we need to continue to search for a more complete perspective and added certainty, even as we acknowledge that we will never arrive at the truth. His approach to the quest for certainty is, therefore, to interpret this quest as a joint search to enhance our understanding of basic educational questions. This ongoing search entails embracing rather than minimizing the complexities, ambiguities, and the risks that are inherent in the field of education.

What I am suggesting here is that in order to gain genuine knowledge about something, it is essential to undergo a rigorous investigation, which involves articulating, doubting, evaluating, and reexamining one's beliefs. Much like Socrates and his dialogue partners, teacher candidates should be encouraged to engage in an active process of inquiry in which their basic beliefs and those of others are subjected to close scrutiny. In the course of this process, it is almost inevitable that these students will become perplexed and unsure of themselves, as Menon did, yet the confusion is an impetus for further investigation. Indeed, the history of science, philosophy, and ideas in general indicates that human advancement has come when people were confused about something and insisted on asking 'Why?' and 'How?' Socrates would surely agree with Theodore Sizer who concludes that "progress comes from seeing something new and compelling in the apparently familiar, teasing out fresh and often better conclusions on the basis of fresh and diligently sought-after evidence" (Sizer, 1996, p. 78).

However, in the course of their training, teacher candidates typically receive a very different kind of message. They learn that instruction has to be crystal clear and that students' learning is stifled when they are confused. Teacher candidates are taught that learning suffers when teachers fail to pursue any clear objectives, ask vague or ambiguous questions, and do not provide enough direct supervision for their students (Brophy, 1986, p. 1071). And they are told that in order to guarantee their students' success, the assessments they use must be very explicit and unambiguous. Loughran and Northfield expand on this point, noting that

In one sense, the greater the certainty associated with the task, the easier (and safer) it is for students to pursue success as they know what they are aiming for. It is interesting to note that when learning tasks move away from being clear and rigid, students begin to become suspicious of change. This can happen when the tasks involve enjoyment. Paradoxically, the introduction of interest and enjoyment in learning can be a signal to students that the demands are changing and that they should be 'on their guard'. (Loughran and Northfield, 1996, p. 128)

My own experience as a teacher educator confirms Loughran's and Northfield's point - that students become suspicious of change when the requirements are flexible and make room for choice and creativity. Many of my teacher candidates became anxious when they were given open-ended projects, required to interpret a text in an individual way, or asked to design a group presentation in which they were given a great deal of choice and room for creativity. These students suggested that they 
would prefer if my assessments were not so open-ended and flexible and that I tell them exactly what they needed to do in order to succeed in these projects.

To be sure, clear expectations and unambiguous assignments make things easier not only for the students but also for teachers who can thereby limit the unexpected occurrences in the classroom, save time and cover more content. However, saving time, controlling risks, and making life easier for teachers are probably not the most important educational objectives. As in many debates, everything hinges on the issue of the underlying purpose of education. Hence if the main purpose is to prepare students to acquire a set of essential facts and skills in the most efficient way possible, then clear expectations and instruction are certainly needed to achieve this goal. But if, as Socrates would probably advocate, the primary aim is to cultivate critical thinkers and individuals with moral fortitude, then the emphasis will need to shift to those methods and techniques that facilitate deeper thinking, inquiry, and self-examination.

Given the uncertain nature of human reality and classroom life, it stands to reason that we need to seriously question the claim that instruction should always be clear and that confusion hurts students. Are teachers not undermining their students' ability to gain a deep understanding of this reality when they present the subject matter in a clear-cut and one-dimensional way? When Christopher Columbus, for example, is presented as simply the courageous European who discovered the new world, as many history textbooks do, are we not robbing children of the opportunity to come to a critical historical awareness of the conquest of the Americas? And when a Robert Frost poem is considered from a single perspective (i.e. the teacher's), will many teenagers, who face confusion and doubt every day, not come away thinking that poetry is not for them because it has nothing to do with their lived experience?

I raise these questions not for the sake of providing a conclusive answer, but in order to call attention to the tension between the claim that teachers' expectations and instruction should be crystal clear and the nature of human reality in general and teaching in particular, which is uncertain and complex. The lesson to learn here is not that teachers should deliberately try to confuse students so that they will better adjust to the uncertain and complex nature of our existence. It is rather that as teachers we should not shy away from those moments of perplexity and uncertainty in our lessons because such moments are opportunities to investigate further and to consider problems from fresh perspectives. In doing so, we will be modeling for our students that a sense of confusion and doubt needs to be embraced, not avoided, as it is likely to result in a deeper awareness of ourselves and our relationship to the world around us.

Moreover, since there is always a gap between what teachers teach and what students actually learn, some level of confusion is inherent in every classroom interaction. That is, the information, directions, and messages that teachers communicate are never understood by all students in the exact way that teachers intend them to be heard. Even if a teacher conveys the ideas in the clearest possible way, there is always a certain measure of uncertainty in the classroom. This is due to the fact that every student is a unique individual and therefore each one interprets and makes sense of the information in a slightly different way. The fact that a measure of uncertainty is inherent in every student-teacher interaction reinforces the point that we should embrace rather than shy away from moments of confusion. By embracing confusion, both teachers and students will gradually learn to take advantage of moments of perplexity in order to dig deeper, consider alternative ideas, and attempt new methods that have not been explored yet. In the last section of this essay, I would like to explore in more detail a number of important implications that the notion of embracing confusion has for teacher education.

\section{Teaching to Embrace Uncertainty}

What would teacher education look like if we were to take seriously Socrates' notion of embracing uncertainty as a way of moving toward critical thinking and self knowledge? To begin with, it seems 
pretty obvious that if we would like teacher candidates to embrace uncertainty, then it seems only reasonable that we, teacher educators, should model this in our teaching. That is, we cannot expect teacher candidates to welcome confusion, if we educators fear their questions and attempt to avoid or minimize them. As Marcy Singer Gabella notes:

If we accept with Dewey that the hallmark of intelligence is the ability both to seek out that which is doubtful and so to attempt to make sense of such problematic situations, and if the purpose of formal education is to cultivate human intelligence, then our schools must become places where uncertainty and ambiguity are cherished, rather than eschewed or merely tolerated. (Gabella, 1995, p. 236).

The key question is: how should educators prepare future teachers for the goal of embracing uncertainty? One reasonable option, discussed by Floden and Buchmann, is to raise teacher candidates' awareness of uncertainty in a way that respects both their need for skills and predictability and the virtues associated with uncertainty like openness, fluidity, and freedom. Floden and Buchmann maintain that

It is, therefore, desirable to help teachers see a greater range of uncertainties than most will discover on their own, even though this may entail raising their levels of anxiety and concern... Raising awareness of hidden uncertainties can draw teachers' attention to more distant, yet inspiring aims, such as long-term learning that is faithful to evolving disciplinary knowledge and ideals of autonomy and responsibility for teachers and students. (Floden \& Buchmann, 1993, p. 378)

Educating students to welcome confusion can also be done through a kind of investigation and questioning that promotes uncertainty. Thinking back on those teachers who had the most impact on me, I realized that most, if not all, of them were skilled at asking very profound, open-ended questions. The questions they asked usually did not have easy and clear-cut answers. Rather, they were complex and difficult problems that lent themselves to multiple interpretations and stimulated diverse opinions and intense discussion. Much like the Socratic dialogues, these discussions typically did not produce any conclusive answers to the questions that were raised. But the process of debating these complex and confusing problems always led my fellow students and me to a deeper understanding of these issues. Ultimately, debating these tough questions taught me the value of being skeptical, of doubting the familiar, of not being content with simple answers, and of searching for alternative viewpoints.

In my foundation courses, I make it a point to challenge teacher candidates to not shy away from moments of confusion, but rather embrace this condition as an integral part of the learning process. For my students, confusion and uncertainty inevitably arise when we read and discuss some of the educational writings of thinkers such as Plato, Rousseau, Dewey, Buber, and Freire. The richness and complexity of these texts typically frustrates many of them because the authors provide the reader with a general educational vision rather than definitive answers or immediate solutions to concrete problems that teachers face. In the face of my students' confusion and frustration, it is tempting sometimes to stop the discussion and just dictate my interpretation of these texts or to give them the answers they are looking for. Yet in doing so, the genuine learning, understanding, and knowledge, which come about when students wrestle with questions, interpret ideas, and attempt to make sense of the world, will be sacrificed.

The challenge facing teacher educators is to accept our students' confusion as a necessary step in gaining a deeper understanding of fundamental educational issues. Following the example of Socrates in Meno, teacher educators should not rush to clarify this confusion but rather acknowledge it as a constructive state of mind. This is by no means an easy thing to do, since it is normal for teachers to want to address their students' needs, answer their questions, and to share their knowledge in the process. Once the confusion has been recognized, the next step is to use it as a point of departure for 
further investigation. One way of doing this is to ask students who are confused about something they read to articulate exactly what they are confused about. In this way, students gain practice in formulating their own interpretations of the text and evaluating them in light of other students' as well as the teacher's positions. When students explain the source of their uncertainty, teachers are able to get a good grasp of whether or not the main concepts of a text have been understood and to relate their students' questions to general critiques of this text.

Another way of helping teacher candidates to embrace uncertainty and complexity is by probing them on those issues about which they seem confident and certain. Teacher candidates in my classes frequently talk about strategies and survival skills that they hope will "work" in the classroom. I often hear comments such as "we need some techniques that can help us control our classes," or "dividing students by ability really worked in my school." When I ask these teacher candidates to reflect on why it is so important for them to control their students or about the underlying purpose of dividing students into ability groups, many of them acknowledge that they have not really thought much about these questions. Basically, they are sidestepping the question of the educational purpose of the methods and techniques they value and immediately moving to consider their practical implementation. Socrates would insist that teacher candidates attend to questions like "what does it mean to control a class?" or "what are some of the ethical problems that the issue of tracking students raises?" Without addressing these questions, teacher candidates will lose an opportunity to become more critical; they may also fail to gain a deep understanding of the techniques they use and decisions they make.

I like to think that I am taking my students on a journey whose outcome is not known in advance, which includes many obstacles along the way, but which holds some genuine rewards for those who are open to learn new things about themselves and about the purpose and nature of education. My experience has taught me that it is essential not to give away everything at the beginning of the course and that it is good to keep some surprises for them along the way. When students go through the process of being confused as they read and discuss a complex text, they gradually learn to ask the tough questions and take fewer things for granted. For most students, the confusion becomes easier to cope with once they accept it as a necessary part of being human and getting to know oneself. Indeed, self-knowledge is important for teacher candidates, as Deborah Britzman and Parker Palmer argue, since it is a topic that has received very little attention in teacher education programs (Britzman, 2000, p. 202; Palmer, 1998, p. 4).

\section{Conclusion: The Value of Welcoming Confusion and Embracing Uncertainty}

In putting so much emphasis on standardization, certainty, and on controlling risks, there is a serious danger that teacher educators may be teaching their students to avoid tough questions, confusion, and a sense of wonder about the world. Being content with a narrowly defined notion of achievement, educators are, in effect, training their students not to think too deeply about important issues, problems, and events. Perhaps teacher educators would be better off embracing confusion and uncertainty. Perhaps those teachers who are doing this and who knowingly ask their students complex and perplexing questions are doing them a service. Indeed, I would argue that they are educating their students to doubt, think critically, to consider issues from multiple perspectives, and to provide convincing arguments for their views.

These goals are far from trivial; as a matter of fact, without them our democracy is in jeopardy. One could probably make a pretty strong case that one of the main reasons that our democracy in the United States is currently being eroded and that so few people are involved in politics is that our nation's schools, media, and other institutions that educate people are not doing their jobs. Instead of teaching people to be critical thinkers and respectful skeptics, these institutions are training them to 
accept the information that is given them without questions, to look for simplistic solutions to complex problems, and to adjust to the status quo. For instance, the majority of the mainstream media in the United States presents the news in a very superficial, one-sided, and mundane way. An atrocity in Africa or Asia gets less attention than the transgressions of celebrities in this country. Without a critical awareness and a complex understanding of social and political issues, individuals will not be able to exercise their right to be active citizens and participators in our democracy. Such an awareness and understanding can only come about if we educate our citizens to embrace confusion, analyze an issue in depth, and to consider a wide range of perspectives before making judgment.

\section{References}

Berman, Louise M. (1999). Teacher as poet. Theory into Practice, 38 (1), 18-23.

Britzman, D. (2000). Teacher education in the confusion of our times. Journal of Teacher Education, 51 (3), 200-205.

Brophy, J. (1986). Teacher influences on student achievement. American Psychologist, 41 (10), 1069-1077.

Dewey, J. (1988). The quest for certainty. In J. Dewey, The later works, Vol. 4: 1929 (Jo Ann Boydston, Ed.; pp. 21-39). Carbondale, IL: Southern Illinois University Press.

Floden, R. E., \& Buchmann, M. (1993). Between routines and anarchy: Preparing teachers for uncertainty. Oxford Review of Education, 19 (3), 373-382.

Hogan, P. (2005). The integrity of learning and the search for truth. Educational Theory, 55 (2), 185-200.

Horn R. A. Jr. (2004). The new federal definition of educational research: Implications for educators. The Teacher Educator, 39 (3), 196-211.

Jackson, P. W. (1990). Life in classrooms. New York: Teachers College Press.

Loughran, J. \& Northfield, J. (1996). Opening the classroom door: Teacher researcher learner. Bristol, PA: Falmer Press.

McDonald, J. P. (1986). Raising the teacher's voice and the ironic role of theory. Harvard Educational Review, 56 (4), 355-377.

Paillotet A. W., \& Callister T. A. (1999). Preparing postformal practitioners: Pitfalls and promises. In J. Kincheloe, S. Steinberg, \& L. Villaverde (Eds.), Retbinking intelligence: Confronting psychological assumptions about teaching and learning (pp. 165-188). New York: Routledge.

Palmer, P. J. (1998). The courage to teach: Exploring the inner landscape of a teacher's life. San Francisco, CA: Jossey-Bass.

Phillips, D. C. (1995). The good, the bad, and the ugly: The many faces of constructivism. Educational Researcher, 24 (7), 5-12.

Schön, D. (1983). The reflective practitioner: How professionals think in action. New York: Basic Books.

Sizer, T. R. (1996). Horace's hope: What works for the American high school. New York: Houghton Mifflin.

Smeyers, P. (2005). Idle search, futile theory, and the risk for education: Reminders of irony and commitment. Educational Theory, 55 (2), 165-183.

Smith R. (2005). Dancing on the feet of chance: The uncertain university. Educational Theory, 55 (2), 139150.

Warmington, E. H., \& Rouse, P. G. (1956). Great dialogues of Plato. (W. H. D. Rouse, Trans.). New York: Mentor Books.

\section{About the Author}

Mordechai Gordon is an Associate Professor of education in the Division of Education at Quinnipiac University. His areas of specialization are teacher education, foundations of education, and democratic education. He is author of Ten Common Myths in American Education (Holistic Education Press, January, 
2005) and the editor of Hannah Arendt and Education: Renewing our Common World, winner of the 2002 AESA Critics Choice Award. Dr. Gordon has published numerous articles in scholarly journals such as Educational Theory, Journal of Thought, and Encounter: Education for Meaning and Social Justice. He can be reached at: Mordechai.gordon@quinnipiac.edu. 